Journal of Engineering and Applied Sciences 14 (13): 4523-4531, 2019

ISSN: 1816-949X

(C) Medwell Journals, 2019

\title{
Simulation of Robust Control of Magnetic Levitation System
}

\author{
Lafta E. J. Alkurawy \\ Department of Electronics Engineering, College of Engineering, University of Diyala, Diyala, Iraq \\ Lafta_67@yahoo.com, lafta.Alkurawy@engineering.uodiyala.edu.iq
}

\begin{abstract}
The designing and analyzing of Magnetic Levitation System (MPC) is very good for control systems because the system is nonlinear unstable with bearings of magnetic and transportation of high-speed and accuracy. The main goal of this study is to design and structure the best controller in robust controllerin optimization manner by $\mathrm{H}_{\infty}$. The mathematical modes of the mechanical is completed, magnetic and electrical system for analyzing are also developed. We will see that the control design is to affect to change the stability state. The main advantages of robust control systems design is to maintain assurance of system performance of model uncertainty. A system is robust when its performance performs adequately under model uncertainty. The design performed under MATLAB codes.
\end{abstract}

Key words: Modeling of manetic levitation system, nonlinear analysis, robust control, optimization, assurance, MATLAB codes

\section{INTRODUCTION}

Magnetic levitation system: Magnetic levitation techniques apply a magnetic field to levitate or suspend a magnetic object based on the interaction between the magnetic object and the applied magnetic field. A magnetic object can be levitated and stabilized ina magnetic system with an electronic feedback control to dynamically adjust one or more electromagnets in the system to stabilize the magnetically levitated object at a desired location. A robust control is provided to control the magnetic field that levitates the magnetic platform to stabilize the levitated magnetic platform.

NaumoviC (2003) the portable magnetic levitation system (Maglev) is away to design control by laboratory experiments. The single axis magnetic levitator of suspended body is empty ball of steel $(20 \mathrm{~g})$ mass and $(25 \mathrm{~mm})$ diameter. This tool was bought to make the learning of control of automatic at theelectronic engineering staffin Nis. The system magnetic levitation and it is components are described. The equations of system are nonlinear and linear models and developed. The maglev system included an analog controller that levitated and stabilized a set of hollow steel balls about an operating region. However, there is little insight known about the model of the plant (NaumoviC, 2003).

Naumovic and Zivanovic (2008) he proposed a model of benchmark laboratory for magnetic levitation system for the control system understanding. It is open loop unstable and nonlinear system. The problems of modeling and control are very challenging by intrinsic nonlinearity. The strategies of control are using both methods of design modern and classical have been implemented in maglev. The system of maglevis not only tasks for research of control engineering but also set up serves as a simple model of devices which are becoming more and more popular in recent years. The system of magnetic levitation have plenty of uses such as in bearings of frictionless, trainsof passenger for high-speed transportation magnetic levitation system, models of wind tunnel, sensitive machinery vibration isolation, molten metal levitation in furnaces of induction, metal slabs levitation and bearings of magnetic. The main objective is to control and analyze robust feedback control for magnetic levitation system. The prominence is on understanding the design method of $\mathrm{H}$ robust control and it is pertinent for magnetic levitation system. The selection of weighting function for synthesis of controller is done with the assistance of the objects. Models by mathematical manner for the magnetic levitation system is founded using objects (Naumovic and Zivanovic, 2008).

Galvao et al. (2003) maglev trains are recently tested and some lines are already available as for example in shanghai. These system with controller were designed by using techniques of standard linear control, focused on an estimate the model by linear manner that discovered by the system dynamics perturbing about a wanted operating point condition. The system of a linear model is reasonable about the operating pointsmall area, the controller of linear controller can only be anticipated in this same region for function. This method design of nonlinear control is commonly used because it is comparatively uncomplicated to linear controller design to 


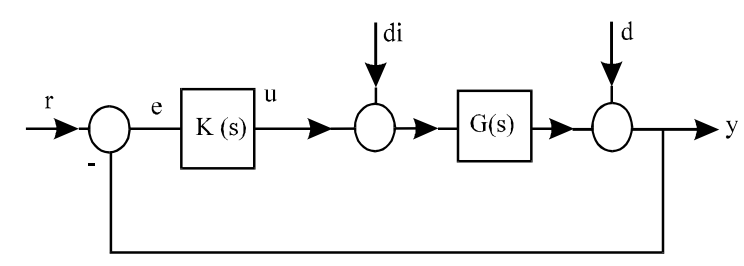

Fig. 1: Feedback control system

make the linear model be stable and thus, the system of non-linear in the operating point neighborhood. This methodology has disadvantages. For example, if the system with a disturbance, so that, it comparatively distant from the operating point condition, it can be unstable. Also, a controller of linear model is normally need some type of gain for operating points to be changed. Our attraction is the learning of techniques of state-space for nonlinear against linear for the position control ball of a steel levitated acting by electromagnetic above the ground as shown in Fig. 1, magnetic bearings are used in turbines for the same reason as maglev trains are being built which is low friction in the bearing itself. Some other magnetic bearings applications include pumps, fans and other rotating machines (Galvao et al., 2003).

Veselic he proposed to design control system by robust control and there is difference for design between models in mathematical manner. The three parameters $\mathrm{Kp}$, $\mathrm{Ki}$ and $\mathrm{Kd}$ (PID) to control magnetic levitation system that has been consider able use in magnetic levitation system by robust controller. Robust $\mathrm{H}$ control theory agreements with robustness much more immediately than other methods. Magnetic levitation system are electromechanical devices that suspend ferromagnetic materials using electromagnetism. Maglev technology has been receiving increasing attention, since, it eliminates energy losses due to friction. Maglev system based on electromagnetism are characterized by open-loop instability and nonlinear dynamics that suggest the need of stabilizing controller. The electrical and computer Engineering department (ECE) has purchased a laboratory-scale maglev system from feedback limited shown in Fig. 1.

To implement a microcontroller-based digital controller that stabilized a $(20 \mathrm{~g})$ steel ball and tracks reference input signal applied to the maglev.

Naumovic (2004) some functions in MATLAB codes are used for controller and simulation of system using set point. The maglev unit allows for the design of different controller and tests in real time using MATLAB and Simulink environment (Naumovic, 2004)

By Park et al. $(1996,1998)$ proposed a linear contactless wafer transport system. This system consists of a wafer carrier, two levitation tracks, two stabilization tracks and a propelling system. Levitation is achieved by using opposing forces produced between electromagnet tracks and permanent magnets assembled on the carrier. A number of electromagnets assembled at the corners of the levitation tracks stabilize the platform by using a simple feedback control. A constant propelling force is obtained by sending specific current patterns to the propulsion coils on the levitation tracks. Yamakawa et al. (1990) reported a magnetic levitation transport system which can carry silicon wafers into a number of process chambers for product fabrication under particlefree conditions. Since, there are no sliding mechanical parts in this system, it does not need lubricants. Therefore, the transport system is free from oil and has a long lifetime. By Morizane et al. (2000), a linear induction motor implemented as the drive system and the attractive force of the motor was used to levitate a transportation stage in wafer distribution industry. The transportation stage consists of a U-shaped part surrounding a straight stationary track. By delivering an AC current to the coils assembled on the stationary track, the induction phenomenon results in enough attraction force to levitate the stage. The vertical position is controlled by tuning the frequency of the $\mathrm{AC}$ currents in coils.

By Wang et al. (1991), a passively levitated stage is proposed. The system consists of a transportation stage, path track and propelling coils. A number of permanent magnets are assembled at the bottom of the transportation stage and the stationary path track. Levitation is achieved due to the opposing force generated between the permanent magnets. Several electromagnets are assembled at the sides of the path track. By delivering the electrical currents in a certain pattern to the electromagnets, the propulsion force is generated and the platform is transported along the path.

\section{MATERIALS AND METHODS}

Modeling of magnetic levitation system: The maglev includes of electrical, mechanical and magnetic systems. The behavior dynamic of magnetic levitationmay be structured by electromagnetic and mechanical study of systems.

The mathematical model maglev system: Apply Kirchhoff's Voltage law in electrical systemnet work for magnetic levitation system with models of electromagnetic network:

$$
V=V_{R}+V_{L} u(t)=i R+L(x) \frac{d i}{d t}
$$


where, i, R, L and $\mathrm{u}$ arecurrent in the electromagnet coil, resistance of coil, inductance of coil and applied voltage input.

The mathematical model for maglev system: Inductors energy stored can be put in writing as:

$$
\mathrm{w}_{\mathrm{e}}=\frac{1}{2} \mathrm{~L}(\mathrm{x}) \mathrm{i}^{2}
$$

Since, electrical power system $\left(\mathrm{P}_{\mathrm{e}}\right)$ the mechanical power system $\left(\mathrm{P}_{\mathrm{m}}\right)$ where:

$$
\begin{aligned}
& P_{e}=\frac{d W_{e}}{d t} \text { and } P_{m}=-f_{m} \frac{d x}{d t} \text {, Therefore }-f_{m} \frac{d x}{d t}= \\
& \frac{d W_{e}}{d t} f_{m}=-\frac{d W_{e}}{d t} \frac{d x}{d t}=-\frac{d W_{e}}{d x}
\end{aligned}
$$

where, $f_{m}$ is recognized as force of electromagnetic. By sub-situating Eq. 2 in the Eq. 3 :

$$
f_{m}=-\frac{d}{d x}\left(\frac{1}{2} L(x) i^{2}\right)
$$

Since, $L(x)=k / x$, therefore, we have:

$$
f_{m}=-\frac{1}{2} t^{2} \frac{d}{x}\left(\frac{k}{x}\right)=-\frac{1}{2} t^{2}\left(\frac{k}{x}\right) f_{m}=\frac{k}{2}\left(\frac{i^{2}}{x^{2}}\right)
$$

Where:

$\mathrm{k}=$ Electromagnet force constant

$\mathrm{x}=$ It is the gap of actual air between ball surface and core face

If $\mathrm{f}_{\mathrm{m}}$ is a force of electromagnetic manufactured by $\mathrm{f}$ is net the ball force and input current, $\mathrm{f}_{\mathrm{g}}$ is the gravity force and force equation can be put it down as:

$$
f_{g}=f_{m}+f=f+m\left(\frac{d^{2} x}{d t^{2}}\right) m \frac{d \nu}{d t}=-f_{m}+f_{g}
$$

Where:

$\mathrm{m} \quad=$ A mass of steel ball

$v=\mathrm{dx} / \mathrm{dt}=$ The ball movement velocity

$\mathrm{f}_{\mathrm{g}}=-\mathrm{f}_{\mathrm{m}}$ and $\mathrm{f}=0$ with equilibrium condition

Model with non-linear: The mathematical non-linear modeling of electro-mechanical for maglev system can be written in terms of differential Eq. 7:

$$
i R+L \frac{d i}{d t}=u(t)
$$

$$
\frac{\mathrm{dx}}{\mathrm{dt}}=v
$$

$$
\begin{aligned}
& m \frac{d v}{d t}=-f_{m}(x, i)+f_{g} \\
& m \frac{d v}{d t}=\frac{k}{2}\left(\frac{i^{2}}{x^{2}}\right)+f_{g}
\end{aligned}
$$

Mathematical linear model: To implementation for analysis and controller design of magnetic levitation system, linearization model go from the non-linear model. The linearization is completed with equilibrium point condition which can be computed from:

$$
\begin{aligned}
& g=f_{m}(x, i) \\
& g=i_{0}, x_{0}
\end{aligned}
$$

where, I, $v$ and $\mathrm{x}$ are states of the system. The force due to the magnitude force $f_{\mathrm{m}}$ and gravity are equal at equilibrium and that the ball levitates due to opposes each other. Considering nominal input voltage produces the corresponding coil current such that the ball reaches at its equilibrium where position $\mathrm{x}=\mathrm{x}_{0}$, we can linearized the model using Taylor's series expansion of $f_{m}(x, i)$ around the equilibrium point $\left(\mathrm{x}_{0}, \mathrm{i}_{0}\right)$ where $\mathrm{x}=\mathrm{x}_{0}+\delta_{\mathrm{x}}$ and $\mathrm{i}=\mathrm{i}_{0}+\boldsymbol{\delta}_{\mathrm{i}}$.

$f_{m}(x, i)=f_{m}\left(x_{0}, i_{0}\right)+\left(\frac{b_{f_{m}}}{b x}\right)_{\left(x_{0}, i_{0}\right)} \delta x+\left(\frac{b_{f_{m}}}{b i}\right)_{\left(x_{0}, i_{0}\right)} d i$

$$
\mathrm{f}_{\mathrm{m}}=\mathrm{f}_{\mathrm{m} 0}-\mathrm{k}_{\mathrm{s}} \mathrm{d}_{\mathrm{x}}+\mathrm{k}_{\mathrm{i}} \mathrm{d}_{\mathrm{i}}
$$

Where:

$$
\mathrm{k}_{\mathrm{s}}=\mathrm{k}\left(\frac{\mathrm{io}^{2}}{\mathrm{xo}^{3}}\right) \text { and } \mathrm{k}_{\mathrm{i}}=\mathrm{k}\left(\frac{\mathrm{i}_{\mathrm{o}}}{\mathrm{xo}^{2}}\right)
$$

Now, the linear magnetic levitation equation can be put it down as:

$$
\begin{gathered}
L \frac{\mathrm{d}}{\mathrm{dt}} \mathrm{di}+\mathrm{Rdi}=\mathrm{u} \\
\mathrm{m} \frac{\mathrm{d} v}{\mathrm{dt}}-\mathrm{k}_{\mathrm{s}} \delta \mathrm{x}+\mathrm{k}_{\mathrm{i}} \mathrm{d}_{\mathrm{i}}=0 \\
\frac{\mathrm{d}}{\mathrm{dt}} \delta \mathrm{x}=v
\end{gathered}
$$




\begin{tabular}{ll}
\multicolumn{2}{l}{ Table1: Physical parameters of magnetic levitation system } \\
\hline Parameters & Values (units) \\
\hline $\mathrm{m}$ (mass) & $0.068\left(\mathrm{k}_{\mathrm{g}}\right)$ \\
$\mathrm{R}$ (resistance) & $9.95(\Omega)$ \\
$\mathrm{L}$ (inductance) & $0.4122(\mathrm{H})$ \\
$\mathrm{K}$ & $6.53 \times 10^{-3}\left(\mathrm{Nm}^{2} / \mathrm{A}^{2}\right)$ \\
$\mathrm{i}_{0}$ & $0.8(\mathrm{~A})$ \\
$\mathrm{x}_{0}$ & $0.012(\mathrm{~m})$ \\
\hline
\end{tabular}

By using Eq. 13-15, we can determine the magnetic levitation state space model as:

$$
\begin{gathered}
\frac{\mathrm{d}}{\mathrm{dt}}\left[\begin{array}{c}
\mathrm{d}_{\mathrm{d}} \\
v \\
\delta \mathrm{x}
\end{array}\right]=\left[\begin{array}{ccc}
-\frac{\mathrm{R}}{\mathrm{L}} & 0 & 0 \\
-\frac{\mathrm{k}_{\mathrm{i}}}{\mathrm{m}} & 0 & \frac{\mathrm{k}_{\mathrm{s}}}{\mathrm{m}} \\
0 & 1 & 0
\end{array}\right]\left[\begin{array}{c}
\mathrm{d}_{1} \\
v \\
\delta \mathrm{x}
\end{array}\right]+\left[\begin{array}{c}
\frac{1}{\mathrm{~L}} \\
0 \\
0
\end{array}\right] \mathrm{u} \\
\mathrm{Y}=\left[\begin{array}{lll}
0 & 0 & 1
\end{array}\right]\left[\begin{array}{c}
\mathrm{d}_{\mathrm{i}} \\
v \\
\delta \mathrm{x}
\end{array}\right]
\end{gathered}
$$

Equation 16 and 17 constitute the state space model $\mathrm{X}=\mathrm{AX}+\mathrm{BX}$ and $\mathrm{Y}=\mathrm{CX}+\mathrm{DU}$ where:

$$
A=\left[\begin{array}{ccc}
-\frac{\mathrm{R}}{\mathrm{L}} & 0 & 0 \\
-\frac{\mathrm{k}_{\mathrm{i}}}{\mathrm{m}} & 0 & \frac{\mathrm{k}_{\mathrm{s}}}{\mathrm{m}} \\
0 & 1 & 0
\end{array}\right] ; B=\left[\begin{array}{c}
\frac{1}{\mathrm{~L}} \\
0 \\
0
\end{array}\right], \mathrm{C}=\left[\begin{array}{lll}
0 & 0 & 1
\end{array}\right]
$$

And $\mathrm{D}=0$. In order to obtain the A-D matrices for the linear maglev model, we consider the physical parameter's value from the following Table 1.

\section{RESULTS AND DISCUSSION}

Robustness: The robust control clearly cares with uncertainty in its manner to design a controller. Robust control method used to design controllers and are capable to manage with little contrasts between the nominal model and actual design for the system. This study is based on design and analysis of robust control. The design and implementation issues of controllers with robustness and the use loop shaping method of $\mathrm{H}_{\infty}$ are inscribed using transfer function and block diagrams along with codes programs in MATLAB. This study is regulated in different sections. A control system is robust when it has low sensitivity, it is stable over the range of parameter variations and the performance continues to meet the specification in the presence of uncertainty. 1stability of system and performance: A system with control of feedback is seen in Fig. 1 the equations for relations will be in detail below:

$$
\begin{gathered}
\mathrm{Sr}=\mathrm{r}-\mathrm{y} \\
\mathrm{Tr}=\mathrm{y} \\
\mathrm{Sr} \mathrm{K}=\mathrm{u}
\end{gathered}
$$

Questions 18-20 make the matrices of feedback move from $r$ to the output $(y-u), u$ and $y$, respectively. We can see from Fig. 1 that $K(s)$ is the controller, $G(s)$ is the nominal plant). Sensitivity and complementary sensitivity $\mathrm{S}$ and $\mathrm{T}$ matrices can see by these questions:

$$
\begin{gathered}
S(s)=(I+K(s) G(s))^{-1} \\
T(s)=K(s) G(s)(I+G(s) K(s))^{-1} \\
=I-(I+G(s) K(s))^{-1}=I-S(s)
\end{gathered}
$$

where, W1 is a component that indicates the required attenuation of disturbance for value of frequency and $\sigma^{-}(\mathrm{S}(\mathrm{jw}))$ is the value of maximum singular of $\mathrm{S}(\mathrm{s})$. We got the low frequency region where disturbance is necessary by good disturbance rejection. We can get $\mathrm{R}(\mathrm{s})=\mathrm{K}(\mathrm{s})$ $\mathrm{S}(\mathrm{s})$ from the transfer function in Eq. 23. Hence, the value of control $\mathrm{u}$ for constraint will be established with component of W2 as seen in Eq. 24:

$$
\left|\sigma^{\sim}(\mathrm{S}(\mathrm{jw}))\right| \leq\left|\mathrm{W}_{2}^{-1}(\mathrm{jw})\right|, \forall \mathrm{w}
$$

The model of the system by mathematical way with uncertainty is discussed as a nominal system by affecting by a perturbation. Upper and lower are for uncertainty of unstructured system. For a perturbations condition that substantial the infinity norm $\|\Delta\|_{\infty}$ we can be modeled with perturbed plant in terms of uncertainty of unstructured system in multiplicative way with relating to $\mathrm{G}$ (nominal plant) as seen in Fig. 2 where:

$$
\mathrm{P}_{\Delta}=\mathrm{G}\left(\mathrm{I}+\Delta_{\mathrm{M}}\right)
$$

where, $\Delta_{\mathrm{M}}=\mathrm{W}_{\mathrm{u}} \Delta$. The structure of frequency of the uncertainty is distinguished by transfer function if it is a stable Wu. In actual systems, test of robustness for stability is wantedunder perturbations system. The 


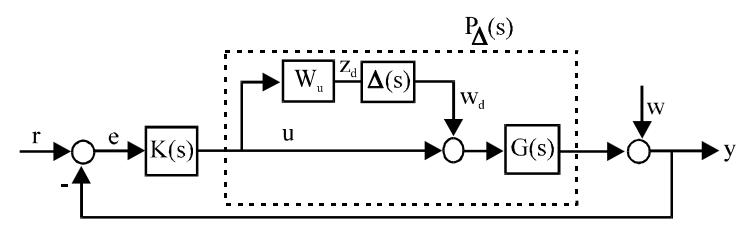

Fig. 2: Uncertainty with multiplicative unstructured

system is stable if Wu as shown in Fig. $2, \Delta_{\mathrm{M}}(\mathrm{s})$ is to be stable of the smallest size for the unstable system is indicated by:

$$
\left|\sigma^{\sim} \Delta_{\mathrm{M}}(\mathrm{jw})\right|=\frac{1}{\sigma^{\sim}(\mathrm{T}(\mathrm{jw}))}
$$

Thus, the bound of upper for $\|\mathrm{T}(\mathrm{s})\|_{\infty}$ can be identified as follows:

$$
\left|\sigma^{\sim} \mathrm{T}(\mathrm{jw})\right| \leq\left|\mathrm{W}_{3}^{-1}(\mathrm{jw})\right|, \forall_{\mathrm{w}}
$$

The function of weighting W3 is used tonoise rejection and good robustness, especially in the range frequency of high value where the error pf modeling are normally important.

A design of typical interconnection is explained in Fig. 3, where the function of weighting W1-W3 indicate the error of steady-state and the attenuation of disturbance, stability condition and controller input constraints, respectively from Eq. 24, 25 and 28 .

Where $\mathrm{w}$ and $\mathrm{u}$ as inputs of the augmented plant and $\mathrm{z}$ and $\mathrm{y}$ as outputs as shown in Fig. 3. The vector of regulated variables $\mathrm{W} 1 \mathrm{~S}, \mathrm{~W} 2 \mathrm{KS}$ and $\mathrm{W} 3 \mathrm{~T}$ as output $\mathrm{z}$.

Where $r$ is the command of reference $r$ and $e=r-y$ is the error of the normal feedback diagram of Fig. 1 related to $y$ and wof Fig. 3. The relationship of the system between the value of output and the value of inputas indicated in Fig. 3 can be put as:

$$
\left[\begin{array}{l}
\mathrm{z} \\
\mathrm{y}
\end{array}\right]=\mathrm{P}\left[\begin{array}{l}
\mathrm{w} \\
\mathrm{u}
\end{array}\right]=\left[\begin{array}{ll}
\mathrm{P}_{11} & \mathrm{P}_{12} \\
\mathrm{P}_{21} & \mathrm{P}_{22}
\end{array}\right]\left[\begin{array}{l}
\mathrm{w} \\
\mathrm{u}
\end{array}\right]
$$

And:

$$
\mathrm{u}=\mathrm{K}(\mathrm{s}) \mathrm{y}
$$

Applying the value of Eq. 13 in to Eq. 12, the transfer matrix of closed-loop from values of $\mathrm{W}$ to value of $\mathrm{Z}$ could be established as:

$$
\mathrm{T}_{z \mathrm{~W}}=\mathrm{P}_{12} \mathrm{~K}\left(\mathrm{I}-\mathrm{P}_{22} \mathrm{~K}\right)^{-1} \mathrm{P}_{21}+\mathrm{P}_{11}
$$

A linear Fraction Transformation (LTI) in Eq. 14 which is described by $\mathrm{f}_{1}(\mathrm{P}, \mathrm{K})$ where ' 1 ' diclerates lower LFT.

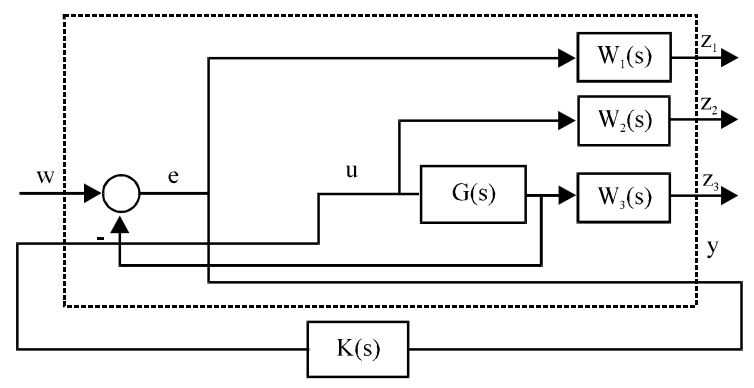

Fig. 3: Augmented plant with weighting function

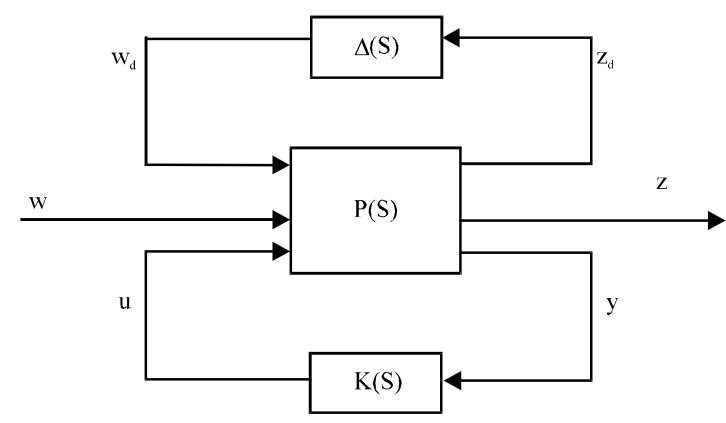

Fig. 4: General block of model with uncertainty

Now, we have uncertainty block with 3 block system as shown in Fig. 2-4. Applying the $\mathrm{f}_{1}(\mathrm{P}, \mathrm{K})$, LFT and we can recuced the blocks in Fig. 4 to two block (M- $\Delta$ ) structured as shown in Fig. 5:

$$
\begin{gathered}
{\left[\begin{array}{c}
\mathrm{z}_{\mathrm{d}} \\
\mathrm{z}
\end{array}\right]=\mathrm{P}\left[\begin{array}{l}
\mathrm{w}_{\mathrm{d}} \\
\mathrm{w}
\end{array}\right]=\left[\begin{array}{ll}
\mathrm{M}_{11} & \mathrm{M}_{12} \\
\mathrm{M}_{21} & \mathrm{M}_{22}
\end{array}\right]\left[\begin{array}{c}
\mathrm{w}_{\mathrm{d}} \\
\mathrm{w}
\end{array}\right]} \\
\mathrm{w}_{\mathrm{d}}=\Delta \mathrm{z}_{\mathrm{d}}
\end{gathered}
$$

Now, we will put Eq. 16 into 15 and get:

$$
\begin{gathered}
\mathrm{z}=\mathrm{F}_{\mathrm{u}}(\mathrm{M}, \Delta) \mathrm{w} \\
\mathrm{z}=\left[\mathrm{M}_{22}+\mathrm{M}_{21} \Delta\left(\mathrm{I}_{\mathrm{M}} \mathrm{M}_{11} \Delta\right)^{-1} \mathrm{M}_{12}\right]
\end{gathered}
$$

where, $\mathrm{u}$ declerates upper of linear fraction transformation and matrix of the transfer from vector of the output $z$ to reference w from Eq. 17 is got by:

$$
\mathrm{T}_{\mathrm{zW}}=\mathrm{F}_{\mathrm{u}}(\mathrm{M}, \Delta)
$$

Design procedure: We define some terms in the beginning, $\mathrm{W} 3$ for complementary sensitivity $\mathrm{T}, \mathrm{W} 1$ for sensitivity $\mathrm{S}$ and $\mathrm{W} 2$ for $\mathrm{KS}$ the W1. The function W3 


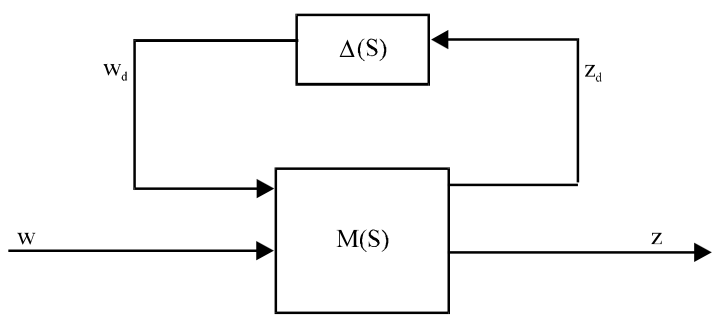

Fig. 5: M- $\Delta$ structure

fulfills the maximum demand on the complementary sensitivity function $\mathrm{T}$ in order to make smaller the oscillation of the system and to determine the values of $\mathrm{T}$ in values of the range the stability of high-frequency. Function $\mathrm{W} 1$ is the sensitivity function bound and rejection of reflects external disturbance, error of steady state is small with respect to the tolerance of plant variations and required equilibrium, W2 weights KS reflecting the constraints of control inputs.

The case for the system the transportation of high speed a $10 \%$ difference the parameters of mass uncertainty considering is incorporated as parameter uncertainty and we can write the variation as: $\mathrm{M}=0.1 \delta+\mathrm{M}$ where $M=$ the steel ball mass and $-1 \leq \boldsymbol{\delta} \leq 1$. The expression $1 / \mathrm{M}$ can be written as:

$$
\frac{1}{\mathrm{M}}=\frac{1}{\mathrm{M}}-\frac{0.1}{\mathrm{M}}(1+0.1 \delta)^{-1}
$$

By comparing Eq. 42 with Eq. 16 the lower fraction transformation matrix M1 can be written as [ ]:

$$
\mathrm{M} 1=\left[\begin{array}{cc}
-0.1 & 1 \\
-0.1 & 1
\end{array}\right]
$$

This LFT can be represented as:

$$
F_{u}\left(\delta,\left[\begin{array}{cc}
-0.1 & 1 \\
-0.1 & 1
\end{array}\right]\right)
$$

Initially, changing $10 \%$ of mas in the plant, weight the complementary sensitivity function $\mathrm{T}$ by selected the W3.

\section{Design of $H_{\infty}$ controller:}

$$
\left\|\mathrm{T}_{z w}\right\|_{\infty}=\left\|\left[\mathrm{W}_{1} \mathrm{~S}_{\mathrm{W}} \mathrm{WS} \mathrm{W}_{3} \mathrm{~T}\right]^{\mathrm{T}}\right\|_{\infty} \leq \gamma
$$

where, $\gamma<1, T_{z w}$, the transfer matrix is the relationship $T_{\mathrm{wz}}$ between disturbance attenuation and robust control of $\mathrm{w}$ base for the disturbance inputs as indicated by Eq. 14 .

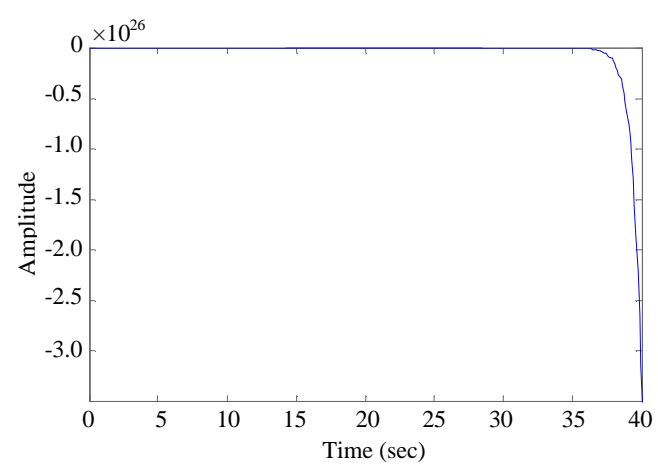

Fig. 6: Step response

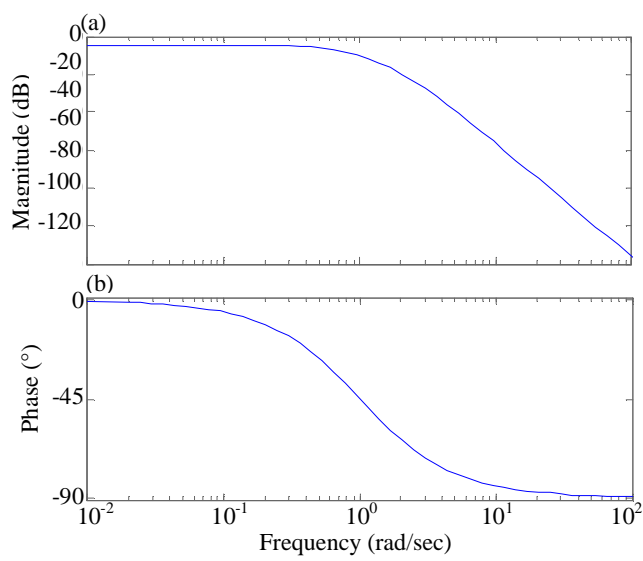

Fig. 7: a, b) Bode plot

The structure of $\mathrm{H}_{\infty}$ control incorporate specifications of performance, rejection of disturbance, limitations of control input and requirements of robustness. The plant of nominal system $\mathrm{G}$ is got by developing the models by mathematical ways indicate above in section 3 . The plant of nominal system $\mathrm{G}$ for which weights $\mathrm{W} 1$ and $\mathrm{W} 3$ are choosing for $\mathrm{H}_{\infty}$ controller that is generated in MATLAB to ensure stability requirements and the performance (Park et al., 1998).

Procedure and result: The state space equation gives the transfer function choosing values for $\mathrm{R}, \mathrm{L}, \mathrm{Ki}, \mathrm{M}, \mathrm{Ks}$ and Ka and by MATLAB code (Fig. 6-12):

$$
[[b, a]=\operatorname{ss} 2 t f(A, B, C, D)
$$

And we can get the transfer as below:

$$
\begin{aligned}
& \mathrm{b}=0-0.00000-1.5000 \\
& \mathrm{a}=1.00001 .0000-2.5000-2.5000
\end{aligned}
$$

Transfer function: 


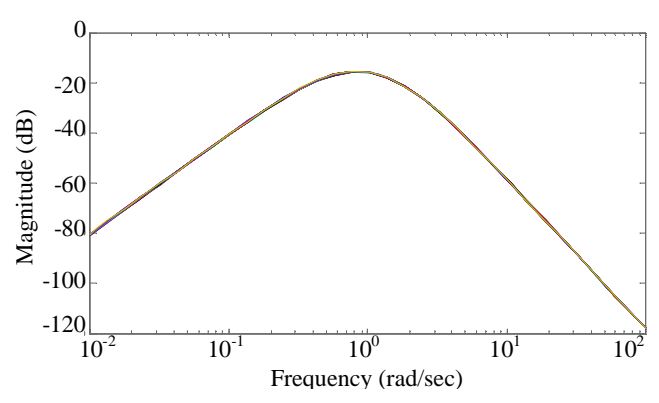

Fig. 8: GP-G $\mathrm{G}_{\text {norm }}$

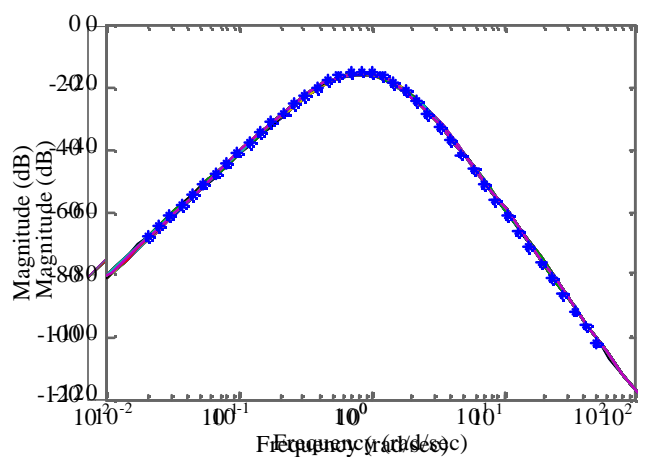

Fig. 9: Additive uncertainty (1A)

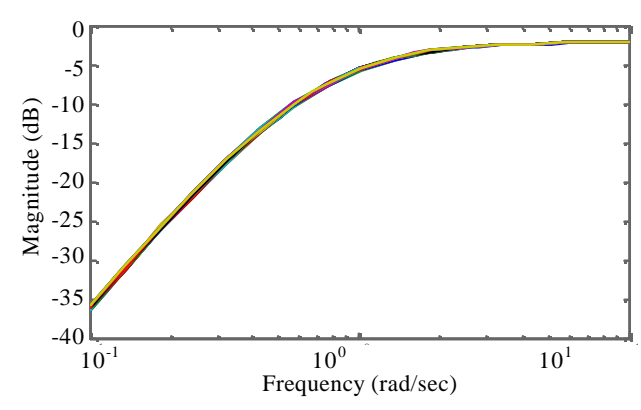

Fig. 10: $G_{\mathrm{p}}-\mathrm{G}_{\text {nom }} / \mathrm{G}_{\text {nom }}$

$$
\mathrm{G}(\mathrm{s}) \text { norms }=\frac{-1.5}{\mathrm{~s}^{\wedge} 3+\mathrm{s}^{\wedge} 2-2.5 \mathrm{~s}-2.5}
$$

And we can test the transfer function with step input and bode plot and get the Fig. 4 and 5 . We see that the system is unstable for varying in frequency and used the robust control to get good condition and performance for system in $\left\|\mathrm{H}_{\infty}\right\|$ but in the we must find the value $1 \mathrm{~A}$ and $\mathrm{II}$. We have equation to find $1 \mathrm{~A}(\mathrm{w})$ :

$$
1 A(w)=\max _{G^{p \in \pi}}\left|G p(j w)-G_{n o m}(j w)\right|
$$

And we have equation to find $1 \mathrm{I}(\mathrm{w})$ :

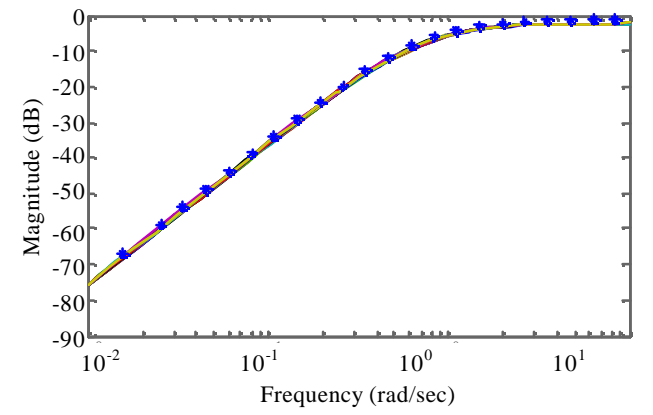

Fig. 11: Multiplicative uncertainty (II)

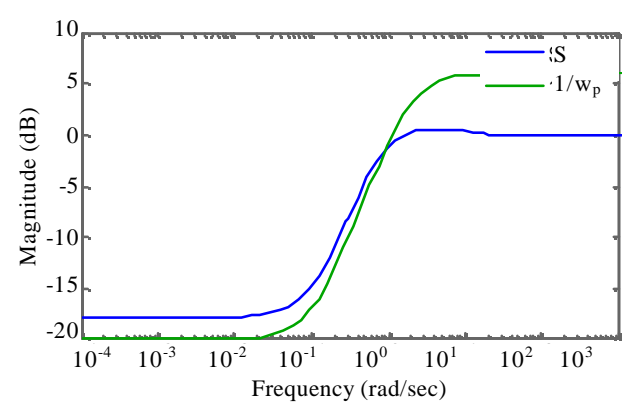

Fig. 12: Sensitivity $S$ and performance weight $\mathrm{w}_{\mathrm{p}}$
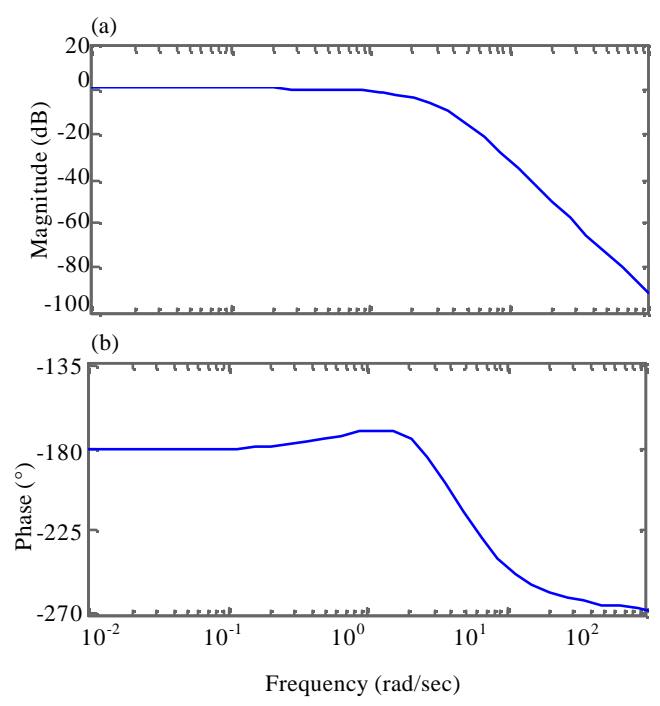

Fig. 13: a, b) Bode diagram for the system after controller

$$
1 A(w)=\max _{\mathrm{Gp} \in \pi}\left|\frac{\mathrm{Gp}(j w)-\mathrm{G}_{\text {nom }}(j w)}{\mathrm{G}_{\text {nom }}}\right|
$$

Figure 6 shows $\left(\mathrm{Gp}-\mathrm{G}_{\mathrm{nom}}\right)$ and that represent the variasion in Mass between $(M=M+0.1 \delta)$ and $-1 \leq \boldsymbol{\delta} \leq$ and Fig. 7 shows that the $1 \mathrm{~A}(\mathrm{w})$ from Eq. 44 to evaluate this value by trial and error to find transfer function to use it later in my work. By the same procedure, we can find $\mathrm{I}(\mathrm{w})$ from Eq. 45 and see that in Fig. 13-17. 


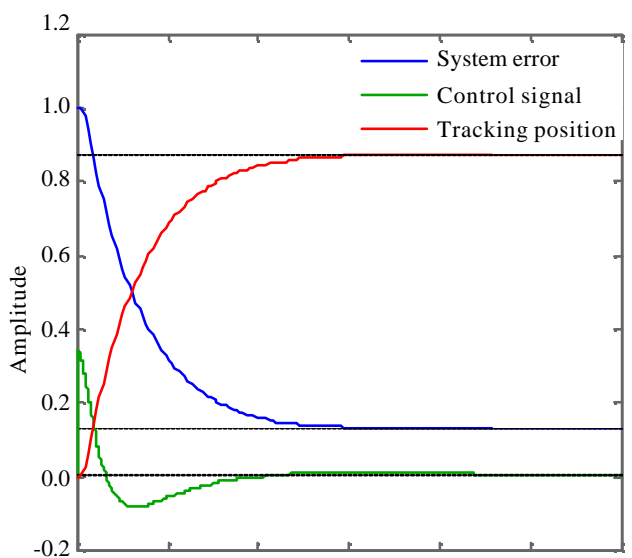

Fig. 14: Response of unit step for system error, control signal and tracking poisition

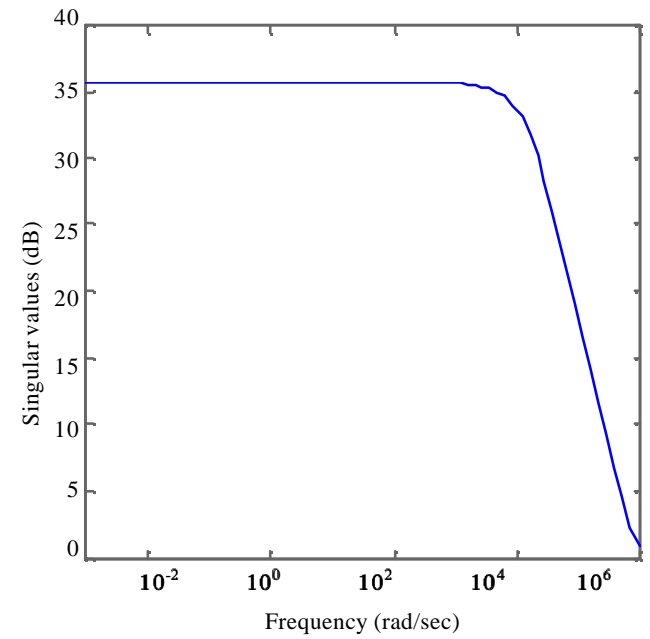

Fig. 15: Nominal stability

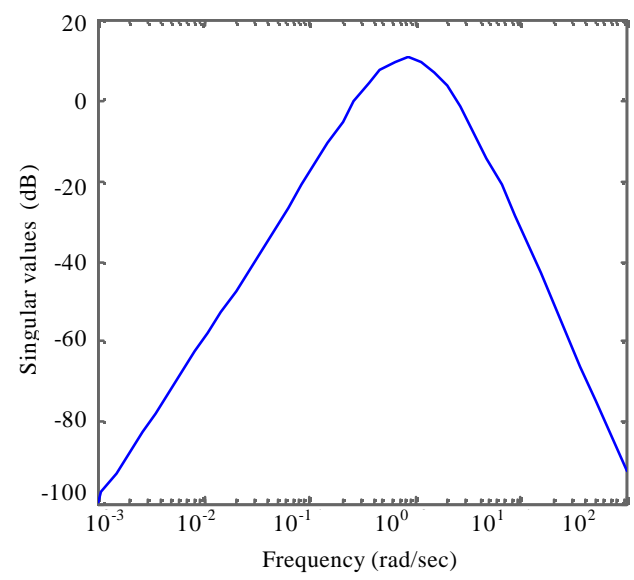

Fig. 16: Robust stability

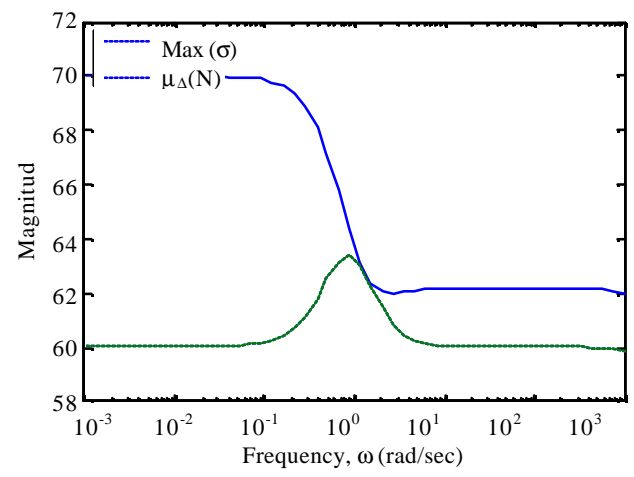

Fig. 17: Robust performance

\section{CONCLUSION}

In this study, we proposed a method to design robust controller with evaluation of experimental manner for a system of nonlinear magnetic levitation which is modeled with state-space and be linearizable by a nonlinear feedback method. The suggested method includes control of linear $\mathrm{H}_{\infty}$ and the state feedback of non-linear by state-space linearization. The essential concept behind the suggested method is that the $\mathrm{H}_{\infty}$ control methodology method will be reasonable to manage with uncertainties of unstructured system and technique of the exact linearization would be totally effectual to subdue the plant structured nonlinearity. In addition, relating to the linearization, we convert the model of nonlinear system to the linear system which is precisely identical of linear approximation of the first order for the original system. As for the appraisal, we have put in for the proposed method of $\mathrm{H}_{\infty}$ control to a simple magnetic levitation system, we got a good results for unconstructed uncertainties and robustness stabilities.

\section{REFERENCES}

Galvao, R.K.H., T. Yoneyama, D.F.M.U. Araujo and R.G. Machado, 2003. A simple technique for identifying a linearized model for a didactic magnetic levitation system. IEEE. Trans. Edu., 46: 22-25.

Morizane, T., N. Kimura and K. Taniguchi, 2000. Simultaneous control of propulsion and levitation of linear induction motor in a novel maglev system. Proceedings of the 3rd International Conference on Power Electronics and Motion Control (IPEMC 2000) Vol. 1, August 15-18, 2000, IEEE, Beijing, China, pp: 127-131. 
NaumoviC, M.B., 2003. Modeling of a didactic magnetic levitation system for control education. Proceedings of the 6th International Conference on Telecommunications in Modern Satellite, Cable and Broadcasting Service (TELSIKS 2003) Vol. 2, October 1-3, 2003, IEEE, Nis, Yugoslavia, ISBN:0-7803-7963-2, pp: 783-786.

Naumovic, M.B. and D. Zivanovic, 2008. Remote experiments in control engineering education laboratory. Intl. J. Online Eng., 4: 48-53.

Naumovic, M.B., 2004. Nonlinear state observation in a didactic magnetic levitation system. Proceedings of 39th International Scientific Conference on Information, Communication and Energy Systems and Technologies (ICEST2004), June 16-19, 2004, St. Clement of Ohrid Faculty of Technical Sciences, Bitola, Macedonia, pp: 473-476.
Park, K.H., K.Y. Ahn, S.H. Kim and Y.K. Kwak, 1998. Wafer distribution system for a clean room using a novel magnetic suspension technique. IEEE/ASME. Trans. Mechatron., 3: 73-78.

Park, K.H., S.K. Lee, J.H. Yi, S. Kim and Y.K. Kwak et al., 1996. Contactless magnetically levitated silicon wafer transport system. Mechatron., 6: 591-610.

Wang, I.Y., S.H. Li and I. Busch-Vishniac, 1991. A magnetic levitation transport path. IEEE. Trans. Semicond. Manuf., 4: 145-154.

Yamakawa, H., I. Moriyama, Y. Minamigawa, Y. Maeba and T. Takematsu et al., 1990. Contamination-free transfer of silicon wafers with a magnetic levitation transport system in vacuum. Vacuum, 41: 1843-1845. 